\title{
Effects of Plot Size on Spatial Patterns and Inter-specific Associations of Dominant Tree Species in Secondary Picea Forest
}

\author{
Mengtao Zhang ( $\nabla$ mengtaozhang@sxau.edu.cn ) \\ Shanxi Agricultural University \\ Yuhua Cui \\ Shanxi Agricultural University \\ Youzhi Han \\ Shanxi Agricultural University \\ Yang Guo \\ Shanxi Agricultural University \\ Zhi Zhang \\ Shanxi Agricultural University
}

\section{Research Article}

Keywords: K2 index, Agreement index, Tree groups, Stand spatial structure

Posted Date: January 24th, 2022

DOI: https://doi.org/10.21203/rs.3.rs-1252709/v1

License: (c) (i) This work is licensed under a Creative Commons Attribution 4.0 International License. Read Full License 


\section{Abstract}

The variety of plot area has an impact on the estimation of spatial parameters. However, accuracy of tree species pattern and inter-specific association is closely related to the estimation of spatial parameters. Based on this, we used different plot sizes, unabridged plot and combined plot to explore the impact of plot size on species spatial pattern and inter-specific associations. 4-ha reference plot of secondary Picea forest was divided into 4 complete 1-ha plots, 10 combined 1-ha plots, and 16 0.25-ha plots. According to the importance value, the tree species were divided into four tree groups, namely Picea, Larix principis, Betula, and other broadleaf trees. $K 2$ index was used to analyze the spatial pattern and inter-specific correlation, and the agreement of these spatial indicators between subplots and reference plot were quantified with agreement index. The results show that: 1) the values of agreement observed that combined 1-ha $>$ unabridged 1-ha $>0.25$ ha, and variability order was opposite; 2 ) under the same plot size, agreement with reference plot was affected by different tree groups or group pairs; 3 ) decrease of plot size had a significant impact on the accuracy of interspecific correlation. This study may have reference value for improving the spatial distribution pattern and inter-specific association of tree species in small-scale sampling plots.

\section{Introduction}

The spatial structure of stand was composed of the spatial pattern of individual trees and the spatial arrangement of stand attributes ${ }^{1,2}$. Spatial pattern of tree species plays a vital role in analyzing the ecological process and coexistence mechanism of plant population, as well as effectively predicting the future forest community ${ }^{3}$. Consequently, this spatial indicator had become a critical factor in predicting forest succession ${ }^{4-6}$. The inter-specific correlation between different tree species can be feedback with the spatial distribution pattern of trees. The spatial pattern impacts the species, and the interaction between species is, in turn, reflected in the spatial distribution pattern ${ }^{7}$. Therefore, studying the inter-specific correlation between different species is also very important in the sample plot.

Previous studies showed that the spatial pattern of tree species is affected by various biological and abiotic factors in the community ${ }^{8-9}$. Biological factors mainly include competition, seed transmission, herbivores and human interference ${ }^{10,11}$. In addition, abiotic factors are mainly environmental factors. For instance, Camaro et al. ${ }^{12}$ pointed out that environmental changes can affect the spatial pattern of tree populations when studying the spatial pattern of subalpine forest-alpine grassland ecotones in the Spanish Central pyrenes. However, when studying these biological or abiotic factors, it is necessary to make a very effective estimation of stand spatial parameters, and the sample plot size is an important factor affecting the accurate estimation of stand spatial parameters ${ }^{13}$. Recently, the research on sample plot size mainly focuses on the impact of sample plot size on species diversity, the best sample plot size of forest inventory, and the impact of sample plot size on the accuracy of biomass prediction ${ }^{14-17}$. However, few reports are on stand spatial structure, especially spatial pattern and inter-specific correlation ${ }^{13,18-19}$. Therefore, enriching the impact of different sample plot sizes on spatial stand patterns and inter-specific correlation is critical.

Recently, the analysis of spatial patterns is a widely used method to analyze stand spatial distribution patterns ${ }^{20,21}$. We choose $K 2$ index as our statistical analysis method, which could effectively avoid the impact of "virtual aggregation" on the spatial pattern and inter-specific correlation of tree species ${ }^{22}$. Meanwhile, we take the "Agreement index" ${ }^{23}$ as our judgment standard and try to solve the following problems: 1 ) is there any difference in spatial stand pattern and interspecific correlation under different sizes? 2) Will there be different consistency due to different species or species pairs under the same plot size? 3) Which of different plot sizes has a greater impact on spatial pattern and inter-specific correlation?

\section{Results}




\section{Study sites}

Pangquangou Nature Reserve, Shanxi Province, China, was selected as an analysis site for the current study. It is located in the middle of Luliang mountains in Western Shanxi Province $\left(37^{\circ} 45^{\prime}-37^{\circ} 55^{\prime} \mathrm{N}, 111^{\circ} 22^{\prime}-111^{\circ} 33^{\prime} \mathrm{E}\right){ }^{24}$. The area exhibits the warm temperate monsoon continental climate. The annual average temperature of $4.3^{\circ} \mathrm{C}$, annual precipitation of 822.6 $\mathrm{mm}$ and annual evaporation of $1268 \mathrm{~mm}$. The vegetation type is a deciduous broad-leaved forest in a warm temperate zone. The soil type is brown mountain soil ${ }^{25}$, with an average soil layer thickness of $70 \sim 80 \mathrm{~cm}$, of which the humus layer is $10 \mathrm{~cm}$. The main tree species are Pinus tabulaeformis, Quercus wutaishansea, Populus davidiana, Betula platyphylla, Larix principis, Platycladus orientalis, Picea asperata, etc. ${ }^{26}$

\section{Plots size and univariate spatial point pattern analysis}

Four different types of tree species (Picea, Larix principis, Betula, and other broadleaf trees) are divided according to the important value in the 4-ha plot (Fig. 1), with a total of 6857 trees (Table 1). Different types of tree species groups show different stand characteristics.

Table-1

Basic characteristics of tree species in a 4-ha secondary Picea forests.

\begin{tabular}{|c|c|c|c|c|c|c|c|c|c|}
\hline \multirow{2}{*}{$\begin{array}{l}\text { Species } \\
\text { group }\end{array}$} & \multirow[t]{2}{*}{ Specie } & \multirow{2}{*}{$\begin{array}{l}\text { Number } \\
\text { of trees }\end{array}$} & \multirow{2}{*}{$\begin{array}{l}\text { Total } \\
\text { trees }\end{array}$} & \multicolumn{2}{|c|}{$\mathrm{DBH}(\mathrm{cm})$} & \multirow{2}{*}{$\begin{array}{l}\text { Density } \\
\text { (n ha } \\
-1 \text { ) }\end{array}$} & \multirow{2}{*}{$\begin{array}{l}\text { B- } \\
\text { area }\end{array}$} & \multirow[t]{2}{*}{ SD } & \multirow[t]{2}{*}{ I-Value } \\
\hline & & & & Max. & Mean. & & & & \\
\hline \multirow[t]{2}{*}{ Picea $(P I)$} & Picea meyeri & 19 & \multirow[t]{2}{*}{5330} & \multirow[t]{2}{*}{65} & \multirow[t]{2}{*}{14.54} & \multirow[t]{2}{*}{1332} & \multirow[t]{2}{*}{2.94} & \multirow[t]{2}{*}{10.70378} & \multirow[t]{2}{*}{0.603393} \\
\hline & Picea wilsonii & 5311 & & & & & & & \\
\hline $\begin{array}{l}\text { Larix } \\
\text { principis (La) }\end{array}$ & Larix principis & 442 & 442 & 64.5 & 30.56 & 110.5 & 9.06 & 10.5523 & 0.258561 \\
\hline \multirow[t]{2}{*}{ Betula (Be) } & $\begin{array}{l}\text { Betula } \\
\text { platyphylla }\end{array}$ & 250 & \multirow[t]{2}{*}{555} & \multirow[t]{2}{*}{46} & \multirow[t]{2}{*}{8.49} & \multirow[t]{2}{*}{138.75} & \multirow[t]{2}{*}{1.01} & \multirow[t]{2}{*}{6.224124} & \multirow[t]{2}{*}{0.079564} \\
\hline & $\begin{array}{l}\text { Betula } \\
\text { albosinensis }\end{array}$ & 305 & & & & & & & \\
\hline \multirow{4}{*}{$\begin{array}{l}\text { Other } \\
\text { broadleaf } \\
\text { trees (Oth) }\end{array}$} & $\begin{array}{l}\text { Quercus } \\
\text { wutaishansea }\end{array}$ & 102 & \multirow[t]{4}{*}{330} & \multirow[t]{4}{*}{72} & \multirow[t]{4}{*}{8.61} & \multirow[t]{4}{*}{82.5} & \multirow[t]{4}{*}{1.08} & \multirow[t]{4}{*}{7.959949} & \multirow[t]{4}{*}{0.058502} \\
\hline & $\begin{array}{l}\text { Populus } \\
\text { davidiana }\end{array}$ & 217 & & & & & & & \\
\hline & $\begin{array}{l}\text { Crataegus } \\
\text { sanguinea }\end{array}$ & 4 & & & & & & & \\
\hline & $\begin{array}{l}\text { Sorbus } \\
\text { pohuashanensis }\end{array}$ & 7 & & & & & & & \\
\hline
\end{tabular}

Notes: $\mathrm{DBH}=$ diameter at breast height; $\mathrm{B}$-area = Basal area $\left(\mathrm{m}^{2} / \mathrm{ha}\right) ; \mathrm{SD}=$ Standard deviation; I-Value =Importance value.

Picea (including the Picea wilsonii and Picea meyeri) individuals accounted for the most IV in the whole 4-ha plot. For 4-ha plot, the individual trees were randomly distributed on the scale of $0-1 \mathrm{~m}$, and the scale was expanded to $1-4 \mathrm{~m}$, showing aggregation distribution. With the increase of scale, the distribution showed random distribution. In Subplots (unabridged 1ha, plots $A, B, C$, and $D$ ), Plot $A$ had the same distribution trend as plot $B$. The individual trees are evenly distributed on the scale of $0-1 \mathrm{~m}$, clustered at 2-3m, and randomly or clustered on other scales. In subplot C, individual trees are clustered and 
distributed on a small distance $(\leq 5 \mathrm{~m})$, other scales are mainly randomly distributed, and individual scales are clustered and evenly distributed (Fig. 2). In subplot D, the distribution pattern of trees was aggregation distributed at the $0-4 \mathrm{~m}$ distance, random distribution and aggregation distribution in 4-25m scale. In 16 microplots of 0.25-ha, the individual trees appear aggregation distribution in the small distance $(\leq 5 \mathrm{~m})$, and the other scales are mainly randomly distributed. In the combined plots (combined1 to combinde10 (Com.1 to Com.10)), Picea was randomly distributed on the distance of 0-1m, aggregation distribution appears on the scale of $1-5 \mathrm{~m}$, random distribution was dominant in other scales, and aggregation distribution or uniform distribution was found on individual scales.

The importance value of Larix principis in 4-ha plot was lower than Picea. On the 4-ha reference plot (Fig. 2), the trees are significantly clustered at $0-3 \mathrm{~m}$, clustered at $10-11 \mathrm{~m}$ and $16 \mathrm{~m}$, but regular distributed at $13 \mathrm{~m}$ scale and randomly distributed at other scales. In Subplots, except the changing trend of plot $A$, the observed values of subplots $B, C$ and $D$ all have the same change trend as the reference sample plot. Sample plot A was regularly distributed at 0-1m distance, aggregated at $5 \mathrm{~m}, 11 \mathrm{~m}$ and $23 \mathrm{~m}$, and randomly distributed at other scales. Sample plot B, the individual trees were significantly clustered in the scale range of $0-3 \mathrm{~m}$, with aggregated distribution at $5 \mathrm{~m}$ and $14 \mathrm{~m}$, a regular distribution up to $24-25 \mathrm{~m}$, and random distribution at other scales. Sample plot $\mathrm{C}$, the individual trees were significantly clustered in the scale range of 0-3m, aggregated at $10 \mathrm{~m}$ and $16 \mathrm{~m}$ scales, random distribution at other distance intervals, and there was no uniform distribution in the whole scale range. In plot $D$, the distance of significant aggregation of trees was further shortened to the scale range of $0-1 \mathrm{~m}$. The aggregation distribution was on the scale of $3 \mathrm{~m}$ and $7 \mathrm{~m}$, and the other scales are mainly randomly distributed. Larix principis was clustered and distributed on a small distance $(\leq 5 \mathrm{~m})$ in the eight 0.25 -ha microplots $\mathrm{A} 3$, B1, B3, B4, C3, C4, D2 and D4, and the rest scales are mainly randomly distributed (Fig. 2). Tree species are mainly randomly distributed in other sample plots on the whole scale.In the combined 1-ha plots, the aggregated distribution of Larix principis individuals was mainly concentrated in the small and medium scales, while the random distribution was dominant in the large scale, and the uniform distribution appears on a large distance $(\geq 20 \mathrm{~m})$.

Betula mainly includes Betula platyphylla and Betula albosinensis, with the third important value. In the 4-ha plot (Fig. 3), trees were clustered distribution in the scale range of $0-1 \mathrm{~m}$ and are randomly distributed in other scales. In subplots $A, C$ and $D$, individual trees were significantly clustered on the range of $0-1 \mathrm{~m}$ and are mainly randomly distributed on other scales. In sample plot B, individual trees were randomly distributed in the whole scale. In addition to the absence of Betula on sample plots A2, B2-B4 and C2, Betula was mainly randomly distributed in the full-scale range of the other 0.25-ha micro plots. Betula has regularity in a combination 1-ha plot compared with microplots. The 10 combined plots show that the aggregation distribution was mainly concentrated in the scale range of $0-1 \mathrm{~m}$. The other scales are mainly randomly distributed, and the uniform distribution appears on a larger scale. For example, in the combined plot 6, regular distribution appears at a distance of $\geq 15 \mathrm{~m}$.

Except for the above three tree species groups with important high values, there are also some broad-leaved trees with a small number of tree species and very small important values in the sample plot. These tree species are less than 100 or just more than 100. If they are taken as an analysis object alone, the results will have a large error because of their small number. Therefore, we integrated these tree species into a group and named them "Other broadleaf trees" for analysis. Other broad-leaved tree groups include four tree species: Quercus wutaishansea, Populus davidiana, Crataegus sanguinea and Sorbus pohuashanensis.

For the 4-ha reference plot (Fig. 3), other broadleaf trees were clustered distributed on the scale of 0-2m, but with the increase of scale range, random distribution and aggregation distribution appear alternately. In subplots $B, C$ and $D$, other broadleaf trees were clustered on the scale of $0-3 \mathrm{~m}$, and the other scales are mainly randomly distributed. In the 0.25 -ha plots, trees were clustered distributed in the scale range of $0-1 \mathrm{~m}$ on the C4-D4 sample plot, and the other scales were mainly randomly distributed. The trees in other sample plots are mainly randomly distributed in the whole scale. The individual trees were clustered and distributed on a small distance $(\leq 5 \mathrm{~m})$. The other scales were mainly random distribution, accompanied by aggregation distribution and uniform distribution on very few scales.

Page $4 / 19$ 


\section{The analysis of plots size and bivariate inter-specific association}

To study the influence of different sizes on the inter-specific correlation between different tree species, we used the bivariate $\mathrm{K} 2$ function (the null model of CSR) to analyze among different tree species. The results are as follows.

For the 4-ha reference plot, $\mathrm{Pi}$ - $\mathrm{La}$ (Fig. 4) had a positive correlation on the scales of $2-3 \mathrm{~m}, 11 \mathrm{~m}$ and $23 \mathrm{~m}$, and was independent on other scales. Pi- Be (Fig. 4) had a negative correlation on the scale of $14-15 \mathrm{~m}$ and a positive correlation on the scale of $17 \mathrm{~m}$, other scales were independent of each other. Pi was positively correlated with Oth on the distance of 2$3 \mathrm{~m}$ (Fig. 5), $11 \mathrm{~m}$ and 23m, and the other scales are independent of each other. La - Be (Fig. 5) and La - Oth (Fig. 6) was independent of each other in the whole scale. Be-Oth (Fig. 6) was positively correlated on a small distance and independent on other distance.

In the complete 1-ha sample plot, $\mathrm{Pi}$ - $\mathrm{La}$ (Fig. 4) was independent of each other in the whole scale range in sample plots $\mathrm{A}$ and $B$. In plot $C$, the two tree groups are independent of each other in a small distance range $(\leq 5 \mathrm{~m})$, but the trend was different from the other three subplots. In plot $D$, the two tree groups are negatively correlated on the scale of $0-1 \mathrm{~m}$, and the other scales are independent. Pi -Be's inter-specific correlation (Fig. 4) was mainly independent of each other in all subplots. $\mathrm{Pi}$ - Oth (Fig. 5) was mainly uncorrelated on the whole scale of all subplots, but the two species are positively correlated on the $0-1 \mathrm{~m}$ scale of $\mathrm{C}$ and D. $\mathrm{La}-\mathrm{Be}$ (Fig. 5), in subplot D, was positively correlated in the scale range of $0-1 \mathrm{~m}$, and was mainly uncorrelated in other scales. In addition, the two tree groups are independent of each other in the full-scale range of subplots A, B and C. La - Oth (Fig. 6) and Pi-Be had the same inter-specific correlation, and showed no correlation in the full-scale range of all 1-ha subplots. Betula - Oth (Fig. 6) are independent of each other in the whole scale in plots A, B and D. In plot $C$, there was a positive correlation trend on the scale of $0-1 \mathrm{~m}$, which becomes uncorrelated with the increase of scale.

In the 0.25-ha sample plot, the four tree species pair of $\mathrm{Pi}-\mathrm{La}, \mathrm{Pi}-\mathrm{Be}, \mathrm{Pi}$ - Oth and $\mathrm{Be}$ - Oth have a positive correlation trend in the small-distance range of a small number of sample plots, and the other scales are mainly uncorrelated. The other tree species pair were not correlated in the full-scale range of all 0.25 -ha plots.

The association between tree groups on the combined 1-ha plot was similar to the complete 1-ha plot. La-Be, La-Oth and $\mathrm{Pi}$ - Oth were not correlated in the whole scale. The other tree species pairs showed positive and negative correlation in the whole scale, but mainly uncorrelated.

Taking the agreement index as the standard (Fig. 7), a histogram was used to compare the consistency of the spatial pattern of four tree species in different plots size with species in the reference sample plots. A nonparametric test was performed on the results.

The results showed that both plot size and tree species could significantly affect the agreement index with the reference plot $\left(P_{(\text {size })}=0.000<0.05, P_{\text {(tree species) }}=0.009<0.05\right)$; however, the interaction between them was not statistically significant and not analyzed.

Among different tree species in the same plot size, there was no significant difference in the agreement index between different tree species in the 0.25 -ha sample plot $(P=0.336>0.05)$, and there was no significant difference among tree species in the complete 1-ha sample plot $(P=0.210>0.05)$. However, there was a significant difference in agreement index among different tree species on the combined 1-ha plot $(P=0.001<0.05)$, the highest agreement index of Betula was 0.969 , followed by Picea 0.9183 , then Larix principis 0.8195 , and finally other broadleaf trees 0.696 .

Under the same tree groups with different plot sizes, there were significant differences in the agreement index between the four tree species and the reference plot $\left.\mathrm{P}_{(B e)}=0.003<0.05, \mathrm{P}_{(O t h)}=0.005<0.05, \mathrm{P}_{(P I)}=0.014<0.05, \mathrm{P}_{(L a)}=0.000<0.05\right)$. The four tree species have the same results. There was a significant difference between the combined 1-ha plot and the 
0.25-ha plot. There was no significant difference between the 0.25 -ha plot and the complete 1-ha plot. There was no significant difference between the combined 1-ha plot and the complete 1-ha plot.

Inter-specific association between different species was analyzed, agreement index between the inter-specific correlation of six pairs of species on the 0.25 -ha sample plot. The reference sample plot was lower than 0.35 (the highest was $B e$ - Oth, 0.3111). The agreement index of inter-specific correlation on the 1-ha sample plot varied with different species pairs and was higher than the 0.25-ha sample plot. Except for $L a-B e$ and $L a$-Oth tree species pairs, the average agreement index of other tree species pairs on the combined 1-ha sample plot was greater than the other two seed sample plots (1-ha and 0.25ha).

The results of nonparametric test showed that two variables (tree species pair and plot size) had significant effects on the agreement index with the reference plot $\left(P_{\text {(tree groups pair) }}=0.00 \leq 0.05, P(\right.$ plot size) $\left.) 0.01 \leq 0.05\right)$.

In the same tree species pair, there was a significant difference in the agreement index of 0.25-ha-combination 1-ha and 0.25-ha-complete 1-ha. However, there was no significant difference between the plot of complete 1-ha and combination 1ha. However, the agreement index of tree species on the combined 1-ha plot was higher than the mean value.

In addition, there was no significant difference in the agreement index between different tree species pairs in 0.25-ha and complete 1-ha plots $\left(P_{(0.25-h a)}=0.078 \geq 0.05 ; P_{(\text {Unabridged 1-ha) }}=0.207 \geq 0.05\right)$. However, in the combined 1-ha plot, the agreement index of $L a-B e$ tree species pair was significantly different from other tree species pairs, and its agreement index was 0.212 .

\section{Discussion}

The sample plot of natural secondary forest of Picea crassifolia was selected, belonging to a representative stand in this area ${ }^{26}$. In the reference (4-ha) plot, Picea was randomly distributed in the distance of 0-1 m; however, significantly clustered in the scale of $1-5 \mathrm{~m}$, and the degree of aggregation first increases and then decreases with the increase of distance in the distance of $1-5 \mathrm{~m}$. Then, it becomes random, while the Larix principis, Betula and other broadleaf trees show obvious aggregation distribution in the small scale of $0-5 \mathrm{~m}$. Combined with the important value, the important value of Picea is more than the sum of the important values of the other three tree groups. Therefore, it is reasonable to explain that spruce occupies a dominant position in the whole stand ${ }^{27}$. Combined with the study of Zhou et al. ${ }^{27}$ on the spatial distribution pattern of dead trees of the natural secondary forest of Picea crassifolia in Guandi mountain, we conclude that spruce has a robust self-thinning phenomenon. Larix principis and the other two tree groups belong to sunny tree species, and their distribution in the stand was affected by Picea. This effect resulted in a small number of individuals in the stand, and the self-thinning phenomenon of intraspecific was inapparent. With the renewal of the stand, a significant aggregation distribution on a small scale was formed.

Then, we divided the 4-ha plot into four complete 1-ha plots to further study the distribution of the reduced plots on the same scale. In the results, we found that the distribution of individual trees in a small distance $(\leq 5 \mathrm{~m})$ of 4 -ha plot was not reflected in the complete 1 -ha plots ${ }^{18}$. For instance, in the study of Larix principis, the reference plot is clustered on a small scale but evenly distributed on a small scale in 1-ha subplot a, which is an interesting phenomenon. Observing the distribution of various tree species on 4-ha, the distribution of Larix principis on 4-ha sample plot roughly presents a strip distribution (Fig. 1). For plot A, Larix principis only appears in the upper right corner, which is only a small part of 4-ha sample plot and cannot ultimately show the distribution pattern of 4-ha sample plot. Similar results were also observed in Betula. The analysis results in sample plot B are quite different from those in other sample plots A, C and D; the reason may be that the number of individuals of birch in sample plot B was too small, i.e., only 13. A previous study ${ }^{22}$ points out that it is critical to ensure the accuracy of K2 index analysis results to ensure enough individual trees in the sample plot. However, the individuals of Betula in sample plot B do not meet this requirement and are lower than the individual threshold of $15-20$ 
trees found in the existing literature ${ }^{12,28}$. Combined with GOF $(P=0.5400>0.05)$, there was a large error in the analysis results ${ }^{21}$. Therefore, when analyzing a large-scale sample plot, if the data in a complete small sample plot are obtained separately, it may significantly impact the analysis results because of the geographical location or the number of some individuals. Moreover, it confirms the conclusion of Schurr et al. ${ }^{29}$ that the spatial pattern of trees can produce different distribution results at different distances.

The study reported that 0.25 -ha is the smallest sample to study the spatial distribution pattern of trees ${ }^{28,30,31}$. In this study, 0.25-ha is the unit sample plot composed of 4-ha sample plot, complete 1-ha sample plot and combined 1-ha sample plot, so it is also crucial for the study sample plot of 0.25-ha. However, there is an obvious problem: the individuals of some tree species do not exist in the 0.25-ha sample plot. For instance, the individuals of a birch on the 0.25 -ha sample plot do not exist in individual plots (A2, B2-B4, C2). Therefore, we delete this part of the sample plot during consistency inspection. Given the small plot area, the number of individual trees in the microsample plot (0.25-ha) is much less than the 4-ha or 1ha sample plot. It has low consistency with the reference sample plot (Fig. 7), with significant variability ${ }^{32}$.

The combined 1-ha plot was composed of four random 0.25-ha plots. Compared with the 0.25-ha unit plot, the area of the combined plot becomes larger and the individual trees in the plot also increase, which can effectively reduce the influence of edge effect on the analysis results ${ }^{18}$. Compared with the complete 1-ha sample plot, the unit sample plot of the combined 1-ha sample plot can come from anywhere of the reference sample plot. Compared with the complete 1-ha sample plot, it can contain more information of the reference sample plot. It will not produce the result that the reference sample plot will not appear due to specific geographical restrictions. Through the agreement index (Fig. 7), we found that among the four different species, the agreement index of the combined sample plot was the highest among the three sample plot sizes, and there was a significant difference from the 0.25 -ha sample plot.

\section{Inter-specific association}

In the 4-ha reference plot, whether broadleaf-conifer or conifer-conifer, the inter-specific correlation is mainly independent of each other on the whole scale. However, P-L, P-B and P-O correlations are different from those of other tree groups. On a small distance $(\leq 5 \mathrm{~m})$, Picea is not correlated with other tree species, but it is positively correlated in trend. The reason may be that Picea is an absolute dominant tree species and belongs to shade tree species, and the distribution of other sunny tree species ${ }^{33}$ such as Larix principis was limited by different habitats. On the other hand, the moderate shade produced by spruce is conducive to the renewal of sunny tree species to a certain extent ${ }^{34}$. The inter-specific correlation of different tree species pairs on the complete 1-ha sample plot is different from the reference sample plot in the range of small scale ( $\leq$ $5 \mathrm{~m})$. Such as, in the Picea - Larix principis tree species pair, the changing trend of the observed values of only two subplots $a$ and $B$ on the whole scale is the same as that of the reference plot, but in sample plots $C$ and $D$, the changing trend of positive correlation and negative correlation on a small scale respectively (Fig. 5). Hence, the inter-specific correlation on the subplot is inconsistent with the reference plot. It can also be seen from the agreement index that the maximum agreement index between the complete 1 -ha plot and the reference plot is only 0.498 , because the inter-specific correlation in different subplots is only a part of the reference plot, which is the same as the reason for examining the spatial distribution pattern of a single tree species in different plots.

In the 0.25 -ha sample plot, the number of tree species decreased significantly, and the correlation between different tree species was further divided ${ }^{18}$. A specific inter-specific correlation was formed in the small-scale sample plot ${ }^{35}$. For example, in subplot $D$, among the four 0.25 -ha plots, only plots D2 and D3 reflect the inter-specific correlation of plot D on a small scale, while plots D1 and D4 do not. In addition, the lack of tree species in the micro-sample plot also affects the accuracy of inter-specific correlation of different tree species. 
The inter-specific correlation on the combined 1-ha plot is mainly uncorrelated on the whole scale. However, the good aspect is that there is no lack of tree species in the combined 1-ha plot compared with the plot of 0.25 ha, which is more favorable to the analysis results.

There are some limitations to this study. We only consider the relationship between different tree species and different sizes in the study of spatial patterns. When exploring the spatial pattern and inter-specific correlation of different species in a sample plot, we also need to start from different angles, such as different null models, the relationship between mature and young trees, and the test of the accuracy of the methods used need to be reflected in the follow-up research.

\section{Conclusion}

We explored the effects of different land sizes on the spatial distribution pattern and inter-specific correlation of different tree species in secondary spruce forests. The univariate and bivariate K2 indexes analyzed the spatial distribution pattern and inter-specific correlation. We found that for the 4-ha plot, there was an apparent intraspecific aggregation of tree species in the small distant range $(\leq 5 \mathrm{~m})$, which begins to weaken in the 1-ha. Then the analysis results utterly different from the reference sample plot will appear in the 0.25 -ha, but the intra-specific aggregation phenomenon became significant in the combined sample plots. The inter-specific correlation between different tree species is mainly independent in the 4-ha reference plot. However, there is a small-scale positive or negative correlation in the complete 1-ha plot. In the 0.25-ha plot, the positive or negative correlation distance increases. Finally, the inter-specific correlation between different tree species in the combined 1-ha plot is mainly uncorrelated again. Regarding the agreement index, the value of tree species in different sizes is only the highest in the combined 1-ha sample plot, and the agreement index of Betula was the highest in the combined sample plot. Inter-specific correlation among tree species was in a low agreement index value in the complete 1-ha plot, 0.25-ha plot and combined 1-ha plot.

Therefore, we draw the following conclusions: 1) the values of agreement observed that combined 1-ha > unabridged 1-ha $>0.25$-ha, and variability order was opposite; 2 ) under the same plot size, agreement with reference plot was affected by different tree groups or group pairs; 3 ) decrease of plot size had a significant impact on the accuracy of interspecific correlation. Combined plots are recommended for point pattern research. If inter-specific association research is attached, complete plots should be dominated, and the sample area should be large enough. Our research can provide reference for improving the accuracy of spatial pattern and interspecific correlation of tree species in small-scale plots.

\section{Materials And Methods Data Collection}

For 4-ha secondary Picea forest. All living trees with diameter at breast height ( $\mathrm{dbh}) \geq 5 \mathrm{~cm}$ was identified and labelled, and stem base coordinates $(x, y), d b h$, and height were recorded. According to the plot division method of Carrer et al. ${ }^{18} 4$-ha plot was divided into 4 unabridged 1-ha plots, 16 0.25-ha plots, and 10 combined 1-ha plots (Fig. 8). The combined plots were selected by complete random sampling (4 quadrats were randomly selected from 16 pieces of 0.25 -ha sample plots for combination and repeated 10 times).

\section{Data Analysis}

There are many tree species ( 9 species, 6857 trees) in the full sample plot. We combine the same genus plants and introduce the critical value as the basis for tree species grouping. The greater critical value of tree species, the greater its advantage in the stand ${ }^{36}$. The expression is as follows:

Importance Value $(\mathrm{IV})=\frac{\mathrm{Rde}+\mathrm{Rfr}+\mathrm{Rdo}}{3} \%$ equation (1) 
Where Rde (Relative density) is the ratio of the number of individuals of a species and the total number of individuals, Rfr (Relative frequency) is the ratio of frequency of a species and sum of frequencies of all species, and Rdo (Relative dominance) is the ratio of basal area of a species and total basal area of all the species.

In data analysis, univariate point pattern analysis was used to evaluate the spatial distribution of each tree group, and a bivariate point pattern was used to evaluate the inter-specific correlation between each tree group. Currently, the commonly used point pattern analysis methods mainly include Ripley's $K$ function, pair-correlation function $(g(r))$, and $O$-ring statistics. However, the analysis results of Ripley's $K$ function will have an accumulation effect with the increase of distance ${ }^{37,38}$, thus confusing the analysis results of large-scale and small-scale. In addition, although $g(r)$ function and $O$-ring function can effectively avoid the scale accumulation effect of Ripley's $K$ function, it will also lead to the phenomenon of "Virtual aggregation" due to the existence of spatial heterogeneity of real stand and the non-uniform distribution of tree species, affecting the analysis results. Consequently, we choose the $K 2$ index ${ }^{22}$, which can effectively avoid "Virtual aggregation" as the second-order statistics function, and its relationship with the $g(r)$ function is:

$$
K 2(r)=\frac{d g(r)}{d r} \text { equation }(2)
$$

An estimate of the $K 2$-index for a given pattern can be obtained by calculating the slope of the estimated $g$-function over a small range of scales between $r+\Delta r$ and $r-\Delta r$.

$$
\hat{K} 2(r)=\frac{\hat{g}(r+\Delta r)-\hat{g}(r-\Delta r)}{2 \Delta r}
$$

\section{equation (3)}

The spatial point pattern is analyzed using the univariate $K 2_{11}(r)$ index. The $95 \%$ confidence envelopes were computed from 199 Monte Carlo simulations, and the goodness-of-fit (GoF) test for the null hypothesis was performed. The index value is a negative distance value (below the envelope), indicating aggregation distribution. The index value is a positive distance value (above the envelope), indicating uniform distribution and random distribution between the envelopes. The inter-specific correlation is analyzed using bivariate $K 2_{12}(r)$ index. The value of $K 2$-index in the lower (upper) side of the envelope is a positive (negative) correlation, uncorrelated between the envelopes.

Null model selection is also essential in analyzing stand spatial distribution patterns and inter-specific correlation. In the statistical analysis of spatial patterns in the population, the complete spatial random (CSR) model was used when the species do not show apparent aggregation. The heterogeneous Poisson (HP) model was used when spatial heterogeneity exists within species ${ }^{39}$. Comparing and analyzing the spatial correlation between species in the stand, Yang et al. ${ }^{40}$ proposed to adopt the null model of CSR. Meanwhile, we choose 1 / 2 of the minimum plot side length (half of the side length of 0.25 -ha sample plot, $0-25 \mathrm{~m}$ ) as the observation scale to eliminate the edge effect and make the observation distance of all plots the same ${ }^{41}$.

The agreement index was first proposed by Cort $^{23}$ on the validation of modules, used to accurately judge the error-free degree between the simulated and observed values.

$$
d=1-\frac{\sum_{i=1}^{N}\left(P_{i}-O_{i}\right)^{2}}{\sum_{i=1}^{N}\left[\left|P_{i}^{\prime}\right|+\left|O_{i}^{\prime}\right|\right]^{2}} \text { equation (4) }
$$

Where $O$ represents the $K 2$ index observation value in 4-ha sample plot, and $P$ represents the $K 2$ index observation value in the subplot (four 1-ha plots; 16 0.25-ha plots; 10 combined 1-ha plots), and $P_{i}=P_{i}-\bar{O}$ and $\backslash$ stackrel $\left\{{ }^{\prime}\right\}\{0\}_{i}=O_{i}-\backslash$ stackrel $\{-\}$ $\{0\}$,ind, $\mathrm{x} d=1$ indicates complete consistency, and $d=0$ indicates complete inconsistency. 
The Nonparametric test of SPSS 24.0 was employed to evaluate the effects of different sizes and different tree species on the spatial distribution pattern and inter-specific correlation of tree species. Programita2018 analyzed the intraspecific spatial pattern and inter-specific correlation data of different tree species. R4.1.0 was used to calculate the agreement index.

\section{Data Availability}

The data used to support the findings of this study are available from the corresponding author upon request.

\section{Declarations}

\section{Acknowledgments}

This work was supported by the Youth Program of National Natural Science Foundation of China (31901308). We thank Dr T. Wiegand for use of the Programita software. We also thank the staff of Pangquangou Nature Reserve who investigated with us.

\section{Additional Information}

Conflict of Interest: The authors declare that they have no conflict of interest.

\section{Author contributions statements}

All authors contributed to the study conception and design. Material preparation, data collection and analysis were performed by [Yang Guo., [Zhi Zhang] and [Yuhua Cui]. The first draft of the manuscript was written by [Yuhua Cui] and [Mengtao Zhang]. The article was reviewed by [Mengtao Zhang] and [Youzhi Han] and all authors commented on previous versions of the manuscript. All authors read and approved the final manuscript.

\section{References}

1. Hui, G.Y. \& Gadow, K.V. Quantitative analysis of forest spatial structure. 170-173 (China Science and Technology, 2003).

2. Larson, A.J., \& Churchill, D. Tree spatial patterns in fire-requent forests of western North America, including mechanisms of pattern formation and implications for designing fuel reduction and restoration treatments. For. Ecol. Manag. 267: 74-92(2012).

3. Liao, J.B., Bogaert, J. \& Nijs, I. Species interactions determine the spatial mortality patterns emerging in plant communities after extreme events. Sci. Rep. 5:11229 (2015).

4. Kang, H.B., Zheng, Y.Y., Liu, S.T., Chai, Z.Z., Chang, M.J., Hu, Y.N., Li, G. \& Wang D.X. Population structure and spatial pattern of predominant tree species in a pine-oak mosaic mixed forest in the Qinling Mountains, China. J. Plant Interact. 12: 78-86 (2017).

5. Wiegand, T. \& Moloney, K.A. Rings, circles, and null-models for point pattern analysis in ecology. Oikos.104:209-229 (2004).

6. Wiegand, T., Gunatilleke, S. \& Gunatilleke, N. Species associations in a heterogeneous Sri Lankan dipterocarp forest. Am. Nat. 170: 77-95 (2007).

7. Mokany, K., Ash, J. \& Roxburgh, S. Effects of spatial aggregation on competition, complementarity and resource use. Austral. Ecol. 33 (3):261-270 (2008). 
8. Harms, K.E., Condit, R., Hubbell, S.P. \& Foster, R.B. Habitat associations of trees and shrubs in a 50-ha neotropical forest plot. J. Ecol. 89 (6):947-959 (2001).

9. Liu, Y.Y., Li, F.R. \& Jin, G.Z. Spatial patterns and associations of four species in an old-growth temperate forest. J. Plant Interact. 9 (1):745-753 (2014).

10. Condit, R., Ashton, P.S., Baker, P., Bunyavejchewin S., Gunatilleke S., Gunatilleke N., Hubbell S.P., Foster R.B., Itoh A., LaFrankie J.V., Lee H.S., Losos E., Manokaran N., Sukumar R. \& Yamakura T. Spatial patterns in the distribution of tropical tree species. Science. 288 (5470): 1414-1418(2000).

11. Comita, L.S., Muller-Landau, H.C., Aguilar, S. \& Hubbell, S.P. Asymmetric density dependence shapes species abundances in a tropical tree community. Science. 329: 330-332 (2010).

12. Camarero, J.J., Gutiérrez, E. \& Fortin, M.J. Spatial pattern of subalpine forest-alpine grassland ecotones in the Spanish Central Pyrenees. For. Ecol. Manag. 134:1-16 (2000).

13. Fonton, N.H., Atindogbe, G., Hounkonnou, N.M. \& Dohou, R.O. Plot size for modelling the spatial structure of Sudanian woodland trees. Ann For Sci. 68: 1315-1321(2011).

14. Lackey, L.G. \& Stein, E.D. (2014) Selecting the optimum plot size for a California design-based stream and wetland mapping program. Environ. Monit. Assess. 186:2599-2608.

15. Kwiatkowska, A.J. \& Symonides, E. Spatial distribution of species diversity indices and their correlation with plot size. Vegetatio. 68:99-102 (1986).

16. Meier, E.S. \& Hofer, G. Effects of plot size and their spatial arrangement on estimates of alpha, beta and gamma diversity of plants in alpine grassland. Alp. Botany. 126:167-176 (2016).

17. Henttonen, H.M. \& Kangas, A. Optimal plot design in a multipurpose forest inventory. For. Ecosyst. 2(31):1-14 (2015).

18. Carrer, M., Castagneri, D., Popa, I., Pividori, M. \& Lingua E. Tree spatial patterns and stand attributes in temperate forests: The importance of plot size, sampling design, and null model. For. Ecol. Manag. 407:125-134 (2018).

19. Yang, X.Q., Yan, H.B., Li, B.H., Han, Y.Z. \& Song, B. Spatial distribution patterns of Symplocos congeners in a subtropical evergreen broad-leaf forest of southern China. J. For. Res. 29:773-784 (2018).

20. Ripley, B. The second-order analysis of stationary point processes. J. Appl. Probab. 13(2): 255-266 (1976).

21. Diggle, P.J. Statistical Analysis of Spatial Point Patterns, 2nd ed. (2003).

22. Schiffers, K., Schurr, F.M., Tielbörger, K., Urbach, C., Moloney, K. \& Jeltsch, F. Dealing with virtual aggregation - a new index for analysing heterogeneous point patterns. Ecography. 31(5): 545-555 (2008).

23. Willmott C.J. On the validation of models. Phys. Geogr. 2(2):184-194 (1981).

24. Qin, Z., Han, Y.Z., Zhang, M.T., Chen, H.X. \& Chen, A.L. Study on spatial pattern and inter-specific correlation of Larix principis-rupprechtii forest. For. Res. manag. 4: 80-85 (2019).

25. Sun, X.Y. \& Yin, J.H. Occurrence and classification of soil under shrub vegetation in Guandi mountain forest area of Shanxi Province. For. Sci. tech. 1: 12-13(1994).

26. Yang, X.Q., Shi, C., Wang, X.G., Ma, H.J., \& Yan, H.B. Species composition, structure and spatial distribution of secondary cold-temperate Picea forest in Guandi Mountain, China. Chin J. Appl. Ecol. 28(05): 1421-1430 (2017).

27. Zhou, D.D., Yan, H.B., Li J., Chen, S. \& Yang, X.Q. Quantitative characteristics and distribution pattern of living and dead standing trees of secondary Picea forest in Guandi Mountain, northern China. Chin J of Appl. Ecol. 32(9): 3061-3069 (2021).

28. Zenner, E.K. \& Peck, J.L.E. Characterizing structural conditions in mature managed red pine: Spatial dependency of metrics and adequacy of plot size. For. Ecol. Manag. 257:311-320 (2009).

29. Schurr, F.M., Bossdorf, O., Milton, S.J. \& Schumacher J. Spatial pattern formation in semi-arid shrubland: a priori predicted versus observed pattern characteristics. Plant. Ecol. 173:271-282 (2004).

30. West, P.W. Tree and forest measurement. 167(Springer, 2004). 
31. Wiegand, T., \& Moloney, K.A. Summary Statistics in Handbook of Spatial Point-Pattern Analysis in Ecology (ed. Richard Smith) 40-65 (CRC,2013).

32. Lin, H.T., Lam, T.Y., Gadow, K.V. \& Kershaw, J.A. Effects of nested plot designs on assessing stand attributes, species diversity, and spatial forest structures. For Ecol. Manag. 457: 1-7 (2020).

33. Chen, H.Y.H., Karel, K. \& Kayahara, G.J. Effects of light on growth, crown architecture, and specific leaf area for naturally established Pinuscontorta var. latifolia and Pseudotsugamenziesii var. glauca saplings. Can J. For. Res. 26(7): 1149-1157 (1996).

34. Guo, J.P., Li H.B., Liu, N. \& Zhang, Y.X. Comparison of Responses of Larix principis-rupprechtii and Picea meyeri Seedling Growth to Light Availability and Planting Density under Controlled Environment. Sci. Silv. Sin. 45(2): 53-59 (2009).

35. Kangas, A. Mensurational aspects in Forest inventory-methodology and applications, Kangas A (ed. Maltamo, M.) 5363 (Springer, 2006).

36. Zhang, M.T., Kang, X.G., Meng, J.H. \& Zhang, L.X. Distribution patterns and associations of dominant tree species in mixed coniferous-broadleaf forest in the Changbai mountains. J. Mt. Sci 12(3):659-670 (2015).

37. Zhang, J.T. Analysis of spatial point pattern for plant species. Acta. Phytoecologica Sin. 22(04): 57-62 (1998).

38. Zhang, D.X., Cheng, J.H., Wang, W., Zhang, H.J. \& Liu, T. Distribution characteristic analysis of preferential flow paths in highway slope soils based on O-ring statistic. Trans. Chin. Soc. Agric. Eng. 33(04): 161-168 (2017).

39. Chang, W., Dang, K.L., Wu, P.H. \& Li, M.Y. Spatial pattern of secondary Quercus aliena var.acuteserrata forests in the Qinling Mountains. Acta. Ecol. Sin. 36(04): 1021-102 (2016).

40. Yang, H., Li, Y.L., Shen, L. \& Kang, X.G. 2014.Spatial distributions and associations of main tree species in a spruce-fir forest in the Changbai Mountains area in northeastern China. Acta. Ecol. Sin. 34(16): 4698-4706.

41. Haase, P. Spatial pattern analysis in ecology based on Ripley's K-function: Introduction and methods of edge correction. J. Veg. Sci. 6(4):575-582 (1995).

\section{Figures}
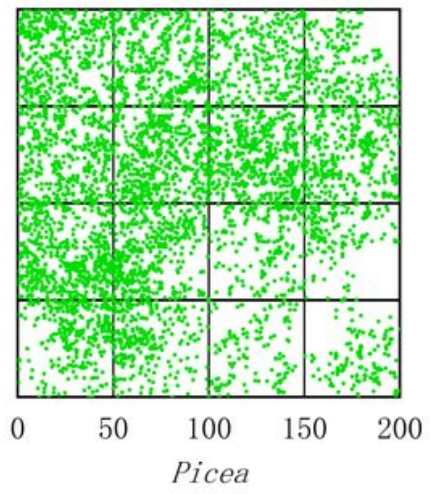

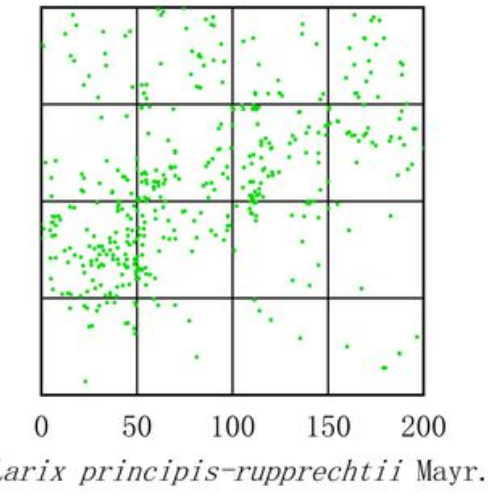

Larix principis-rupprechtii Mayr.
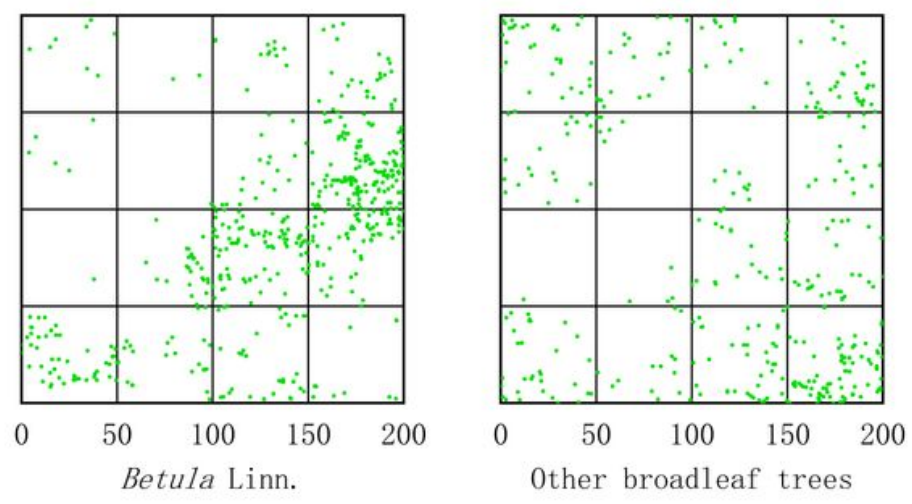

\section{Figure 1}

Maps of trees (green dots) in the 4-ha $(200 \times 200 \mathrm{~m})$ plots at Picea (PI), Larix principis ( La), Betula (Be) and Other broadleaf trees (Oth). 

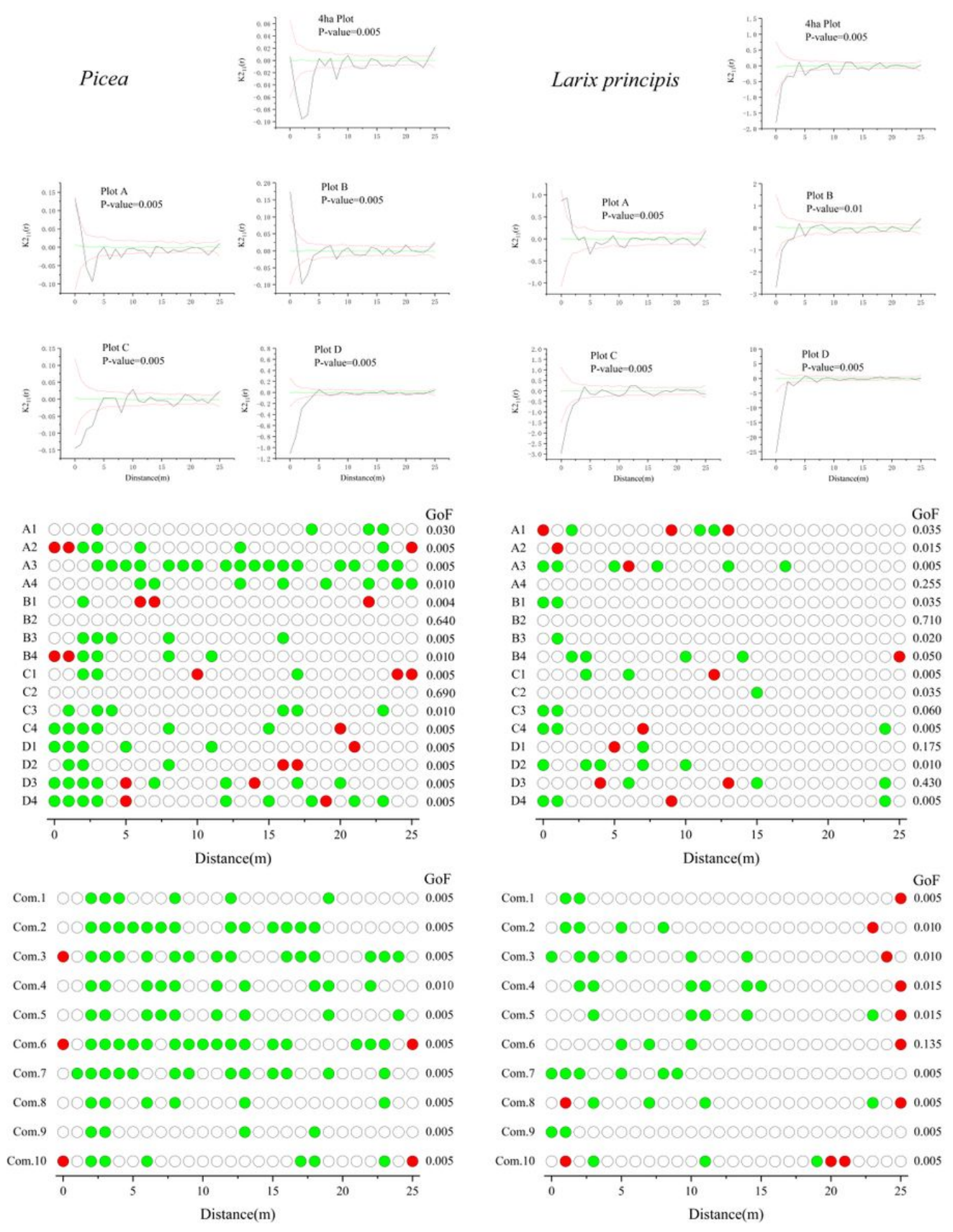

Figure 2

Representation of univariate point pattern analysis of Picea $(P I)$, Larix principis $(L a)$, using complete spatial randomness (CSR) null models, assessed for 4-ha plots and subplots. For 4-ha plots (upper graph) and 1-ha plots (A, B, C and D, below), the black line represents the $\mathrm{K} 2$ index, the green line represents the expected value, and the red dotted line indicate the Monte Carlo envelope (the area between the envelopes was the $95 \%$ confidence interval formed by 199 simulations). For 0.25-ha plots (from A1 to D4), and combined plots (from Com.1 to Com.10), green circles indicate clustering, red circles indicate overdispersion, white circles indicate a random pattern, a gray circle represents a null value. For all the analyses, the $p$-value of the goodness of fitness $(\mathrm{GoF})$ test was reported. 

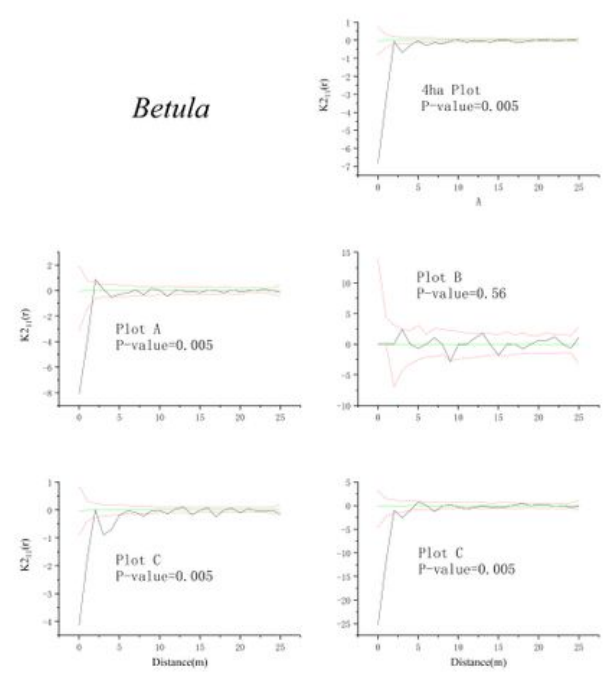

A1 0000000000000000000000000 GoF A1 100000000000000000000000.065 A3 0000000000000000000000000.030 A4 000000000000000000000000000.005 B1 000000000000000000000000.285 B2 $९ 00000000000000000000000000.000$ B3 100000000000000000000000000.000 B4 100000000000000000000000000.000 Cl 000000000000000000000000000.930 c2 000000000000000000 C3 00000000000000000000000000.115 C4 000000000000000000000000000.005

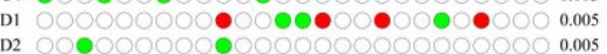
D3 000000000000000000000000000.005
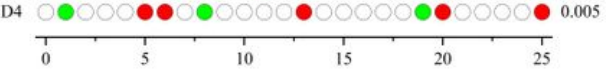

Distance $(m)$

GoF Com 2 ๑000000000000000000000000 0.005 Com.3 ๑ • Com.4 Com.5

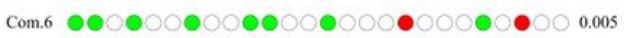

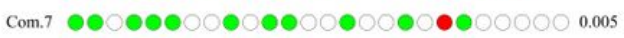
Com.8 Com.9 00000000000000000000000000.005 Com.10 Distance $(\mathrm{m})$
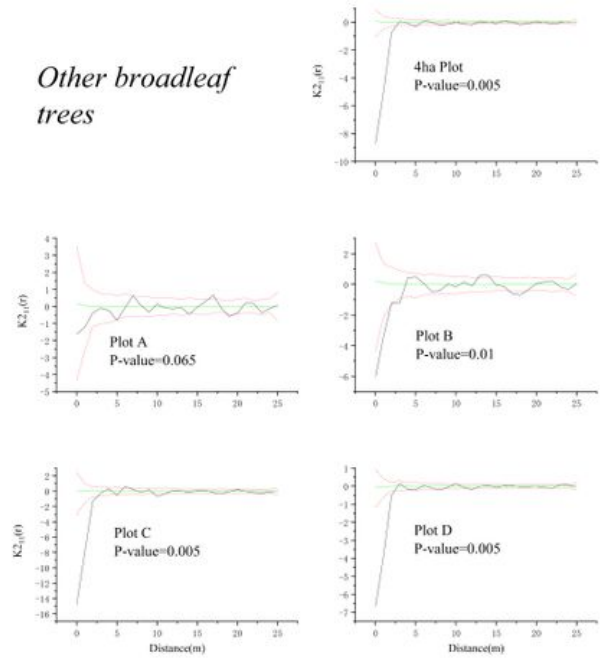

A1 00000000000000000000000000 GoF A1 00000000000000000000000000.200 A2 100000000000000000000000000.000 A3 $0000000 \bullet 0000000000000000.015$ A4 000000000000000000000000000.280 B1 900000000000000000000000000.015 B2 000000000000000000000000000.605 B2 000000000000000000000000000.025

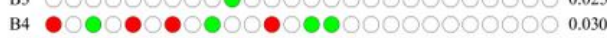
Cl $\mathrm{C} 2$ C3 000000000000000000000000000.085 C4 D1 100000000000000000000000000.005 D1 D2 D3

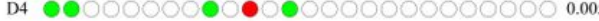
\begin{tabular}{ll|l|l|l|l}
\hline & 1 & 1 & 1 & 1 \\
0 & 5 & 10 & 15 & 20 & 25
\end{tabular} Distance $(\mathrm{m})$

GoF Com.1 $\bullet \bullet \bullet 000000000000000000000.005$ Com.2 0000000000000000000000000.025 Com.3 Com.4 $\bullet 000000000000000 \bullet 00000000.005$ Com.5 Com.6 • Com.7 • Com.8 $\bullet 00000000000000000000000000.005$ Com.9 Com.10 $\bullet \bullet \bullet 0000000000 \bullet 00000 \bullet \bullet 00000.005$

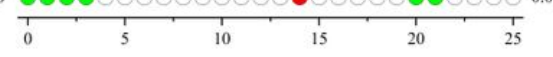

\section{Figure 3}

Representation of univariate point pattern analysis of Betula $(B e)$ and Other broadleaf trees (Oth), using complete spatial randomness (CSR) null models. The detailed descriptions are the same as Fig. 2. 

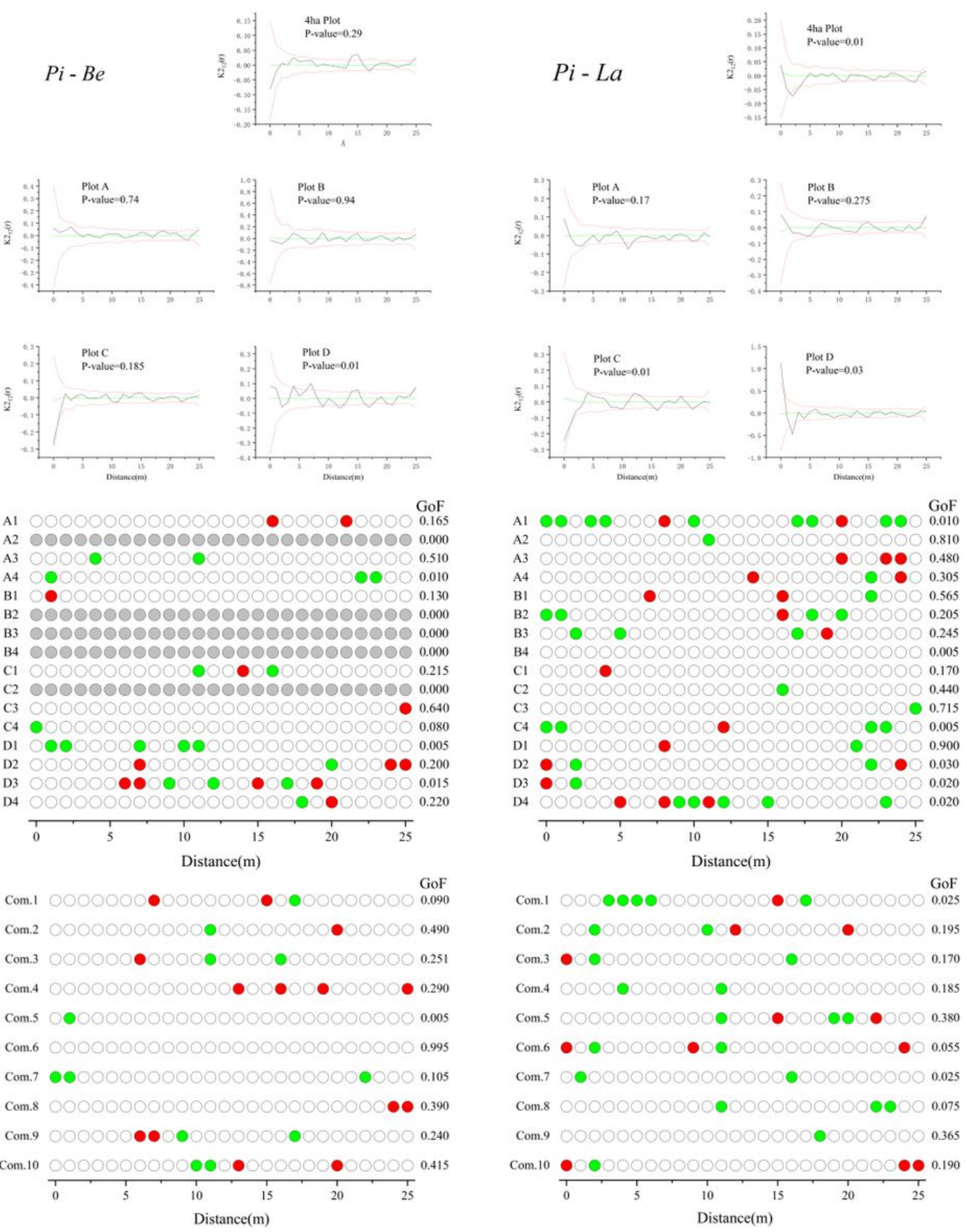

Figure 4

Representation of bivariate point pattern analysis of $P i-B e, P i-L a$, using complete spatial randomness (CSR) null models, assessed for 4-ha plots and subplots. For 4-ha plots (upper graph) and 1-ha plots (A, B, C and D, below), black line represents the K2 index, green line represents the expected value, and the red dotted line indicate the Monte Carlo envelope (the area between the envelopes is the $95 \%$ confidence interval formed by 199 simulations). For 0.25 -ha plots (from A1 to D4), and combined plots (from Com.1 to Com.10), green circles indicate positive correlation, red circles indicate negative correlation, white circles indicate mutual independence, gray circle represents null value. For all the analyses, the $p$ value of the goodness of fitness (GoF) test is reported. 


\section{Pi-Oth}
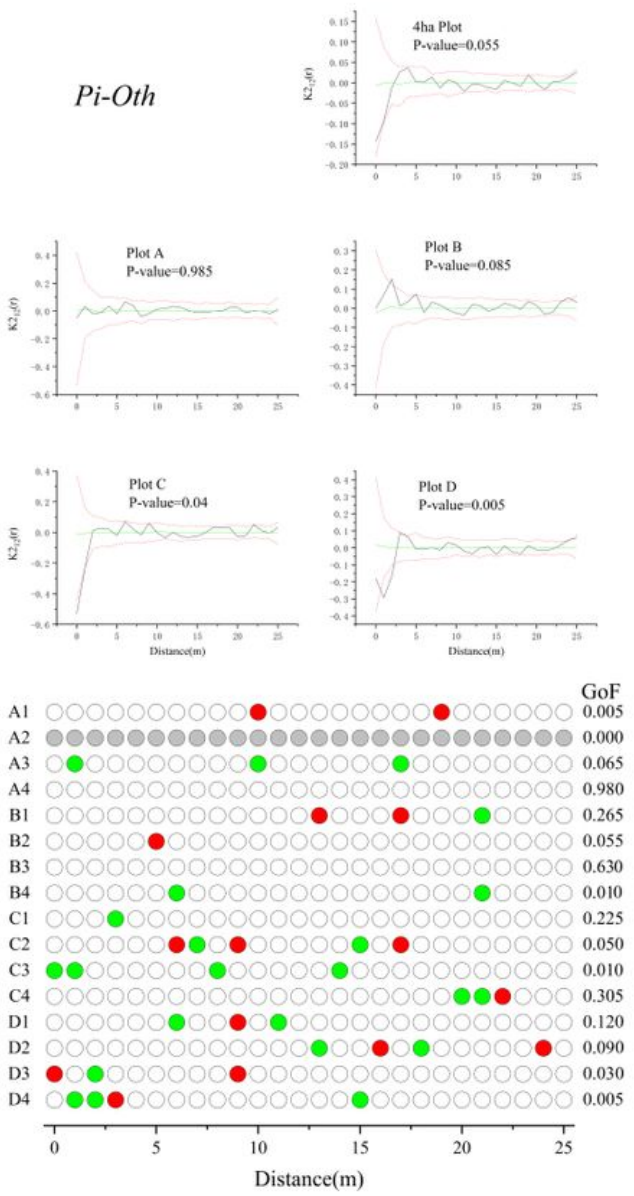

Com.1 $00000000000000000000000000 \quad$ GoF Com.2 $00000 \bullet 0000000000000000000 \quad 0.460$ Com.3 $00000000000000000000000000 \quad 0.340$ Com.4 $000000000 \bullet 000 \bullet 000000000000.680$ Com.5 000000000000000000000000000.725 Com.6 $000000000 \bullet 000000000 \bullet 000000.610$ Com.7 $0000000000 \bullet 00000000000 \bullet 000.135$ Com.8 $0000000 \bullet 000000000000000000.615$ Com.9 $00000 \bullet 000000000000 \bullet \bullet-00000.330$

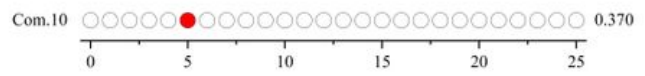
Distance(m)
$\mathrm{La}-\mathrm{Be}$
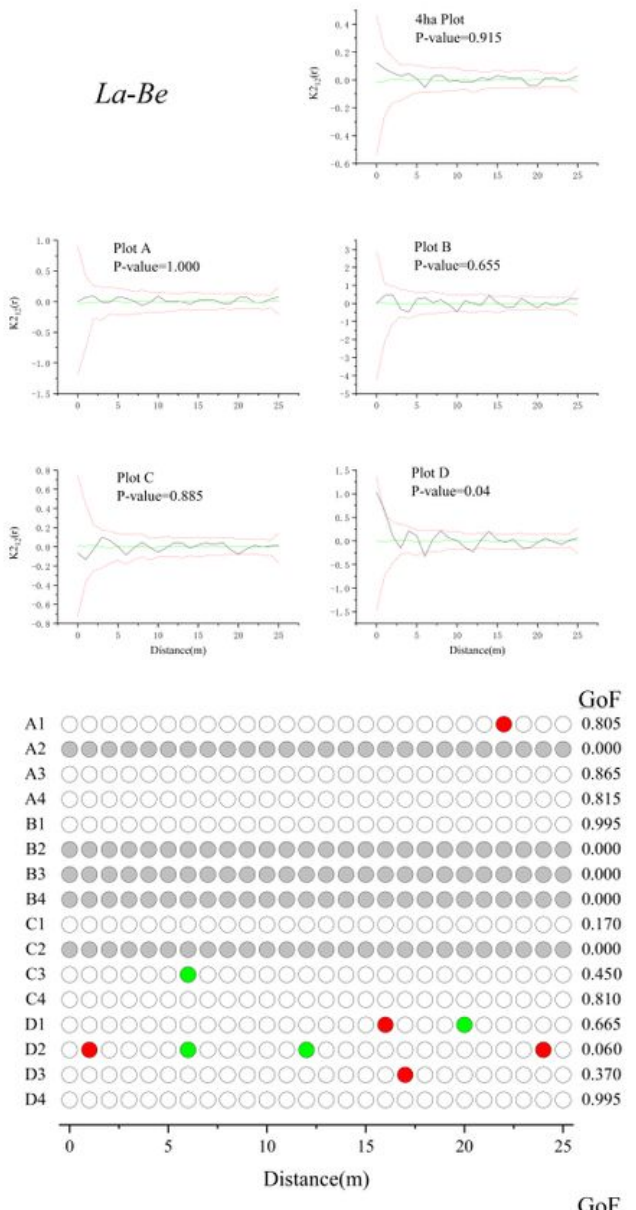

Com.1 000000000000000000000000000.945 Com.2 $00000000000000000000000000 \mathbf{0 . 4 5 0}$ Com.3 000000000000000000000000000.930 Com.4 $000000000000000000 \bullet 00000000.815$ Com.5 000000000000000000000000001.000 Com.6 000000000000000000000000000.940 Com.7 $000000000000000000 \bullet 0000000.690$ Com.8 $0000000000000000000000000 \quad 0.435$ Com.9 000000000000000000000000000.890

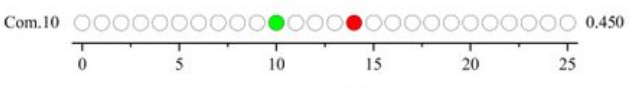
Distance $(\mathrm{m})$

Figure 5

Representation of bivariate point pattern analysis of $P i-O$ th and $L a-B e$, using complete spatial randomness (CSR) null models. The detailed descriptions are the same as Fig.4. 

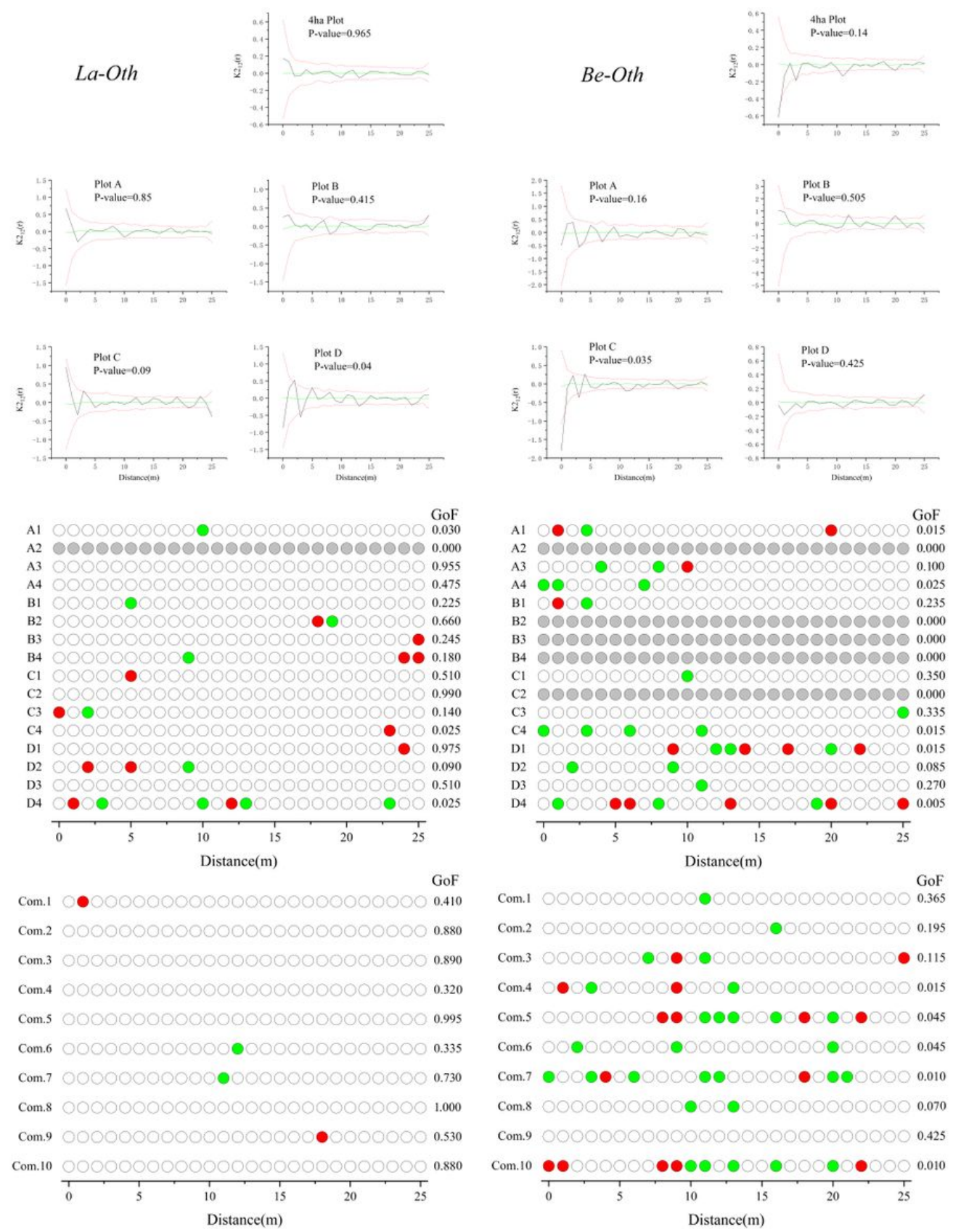

Com.1 00000000000000000000000000 GoF Com.2 000000000000000000000000000.195 Com.3 $00000000000000000000000 \bullet 0.115$ Com.4 $\bullet 00000 \bullet 0000000000000000.015$

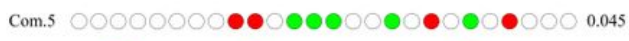
Com.6 000000000000000000000000000.045 Com.7 $00 \bullet \bullet-0000 \bullet 000000 \bullet \bullet 000000.010$ Com.8 $\bigcirc 0000000000000000000000000.070$ Com.9 00000000000000000000000000.425

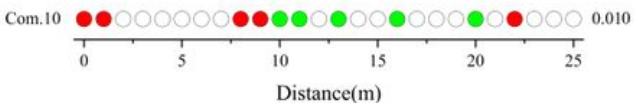

\section{Figure 6}

Representation of bivariate point pattern analysis of $\mathrm{La}-\mathrm{Oth}$ and $\mathrm{Be}-\mathrm{Oth}$, using complete spatial randomness (CSR) null models. The detailed descriptions are the same as Fig.4. 

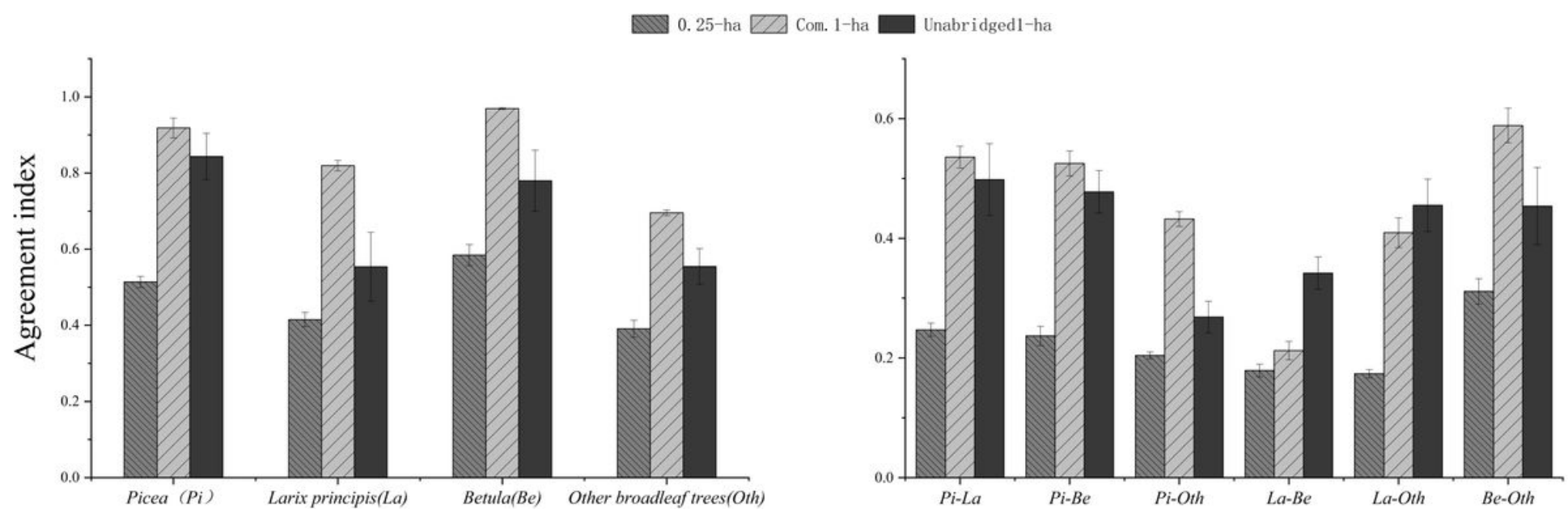

Figure 7

Subplot agreement to the reference for univariate and bivariate point pattern analysis using complete spatial randomness (CSR), at four tree species groups (Picea, Larix principis, Betula, Other broadleaf trees) and six tree species pairs ( $P i-\mathrm{La}, \mathrm{Pi}$ $\mathrm{Be}, \mathrm{Pi}$ - Oth, $\mathrm{La}-\mathrm{Be}, \mathrm{La}-\mathrm{Oth}, \mathrm{Be}-\mathrm{Oth})$. Note that the ordinate ranges of the two figures are different. Bar colors indicate the subplot type (see the legend). 


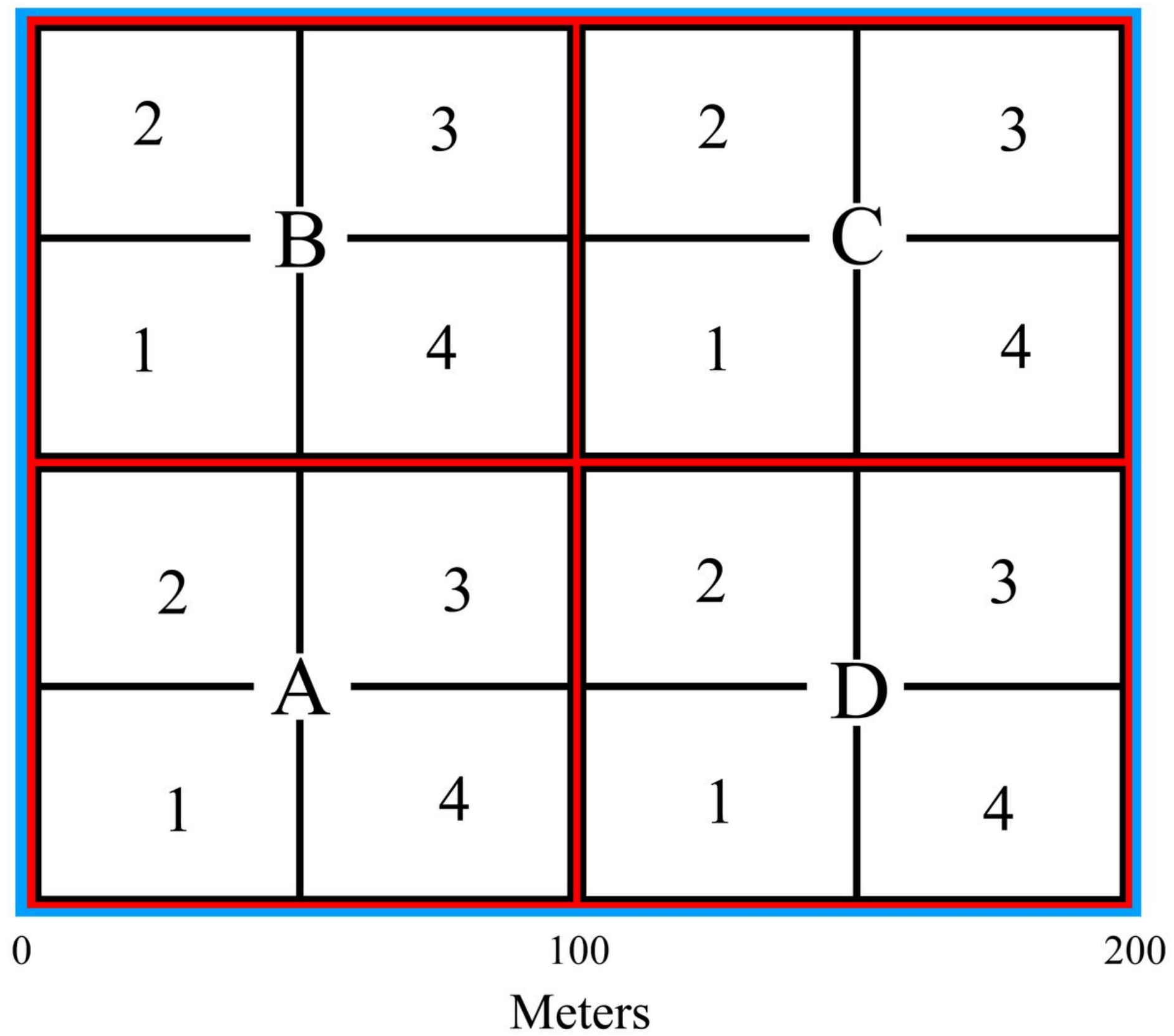

Figure 8

Plot setting in the study. The blue border delineates the 4-ha $(200 \times 200 \mathrm{~m})$ plot. Red borders delineate four 1-ha plots, A, B, C and D. Within 1-ha plots, four 0.25 -ha plots, 1, 2, 3 and 4, are delimited by black borders. The combined plots were randomly sampled from 16 0.25-ha plots, and 4 plots were selected for combination. 